\title{
SOCIAL DETERMINANTS OF COLLECTIVE RESOURCE MANAGEMENT IN BANGLADESH
}

\author{
S. Haque, M. Hossain' ${ }^{1}$ S. Bauer ${ }^{2}$ and F. Kuhlmann ${ }^{3}$ \\ Department of Agricultural Economics, Bangladesh Agricultural University \\ Mymensingh-2202, Bangladesh
}

\begin{abstract}
This paper examines the factors influencing collective action for common resource management. As information base, data sets of 44 brackish water shrimp farming communities in Bangladesh have been used. The result shows that collective action is associated with resource scarcity, market distance from the resource, group size, heterogeneity in the community, and involvement of other institutions. The results tell that while graduates facilitate, outsiders impede collective action. Unlike the findings from other sources, distance to market place has been found very important for common resource management in Bangladesh. Collective action could be more successful, when water user groups are founded through users self motivation, receiving coordination help and technical support from governmental institutions.
\end{abstract}

Key Words: Collective action, Common resource, User's association, Brackish water, Shrimp farming

\section{INTRODUCTION}

Poverty, property rights, institutional and distributional implications of common resource management have become an important focus of discussion and debate in recent times. In rural areas of developing countries, common resource management has especially been considered one of the most viable options for poverty reduction, enhancement of local level economic development, and biodiversity conservation (Adhikari, 2004). According to Wade (1987), water, grazing land and forests - are very important for the livelihoods of people in the developing world. Equally important, however, is the prevention of their overexploitation. The reallocation of control over natural resources from government organizations to user groups has become a general policy in the past decade, especially in terms of community-based natural resource management. The transfer of full

1 Lecturer, Department of Agricultural Economics, Bangladesh Agricultural University, Mymensingh-2202, Bangladesh

2 Institut für Betriebslehre der Agrar-und Ernährungswirtschaft, Professur für Projekt-und Regionalplanung, Senckenbergstraße 3, D-35390 Giessen

${ }^{3}$ Justus-Liebig-Universität Gießen, Institut für Betriebslehre der, Agrar-und Ernährungswirtschaft Senckenbergstraße 3, 35390 Gießen 
responsibility to organized users may increase the participation of the community in resource management.

There is no general consent over whether privatization or state regulation promotes proper use of degraded common resource management. But there are many examples that villagers collectively managing resources for extended periods. Therefore, the third option -local collective action-needs to be considered. Probably less public money is likely to be needed in comparison to either privatization or state dictation. So, it should make financial sense to establish local rules where circumstances permit (Wade, 1987). Balland \& Platteau (1996) and Ostrom (1990) and others demonstrated that local user groups can build institutions to manage their resources sustainable. Local users, who live and work in the area, may have a comparative advantage over government agents in monitoring resource use, since their livelihoods depend on those resources. Therefore, they have the greatest incentives to maintain the resource base over time. In most cases, this trend has been stimulated due to the limitation of government institutions in managing resources at the local level (Meinzen-Dick et al., 2000).

Many researches have been conducted on collective resource management. Still, there exists an intensive debate among scholars on the factors that facilitate or impede collective action in case of common resources. Agarwal (2002) has identified at least two dozen variables which have been recognized by different scholars. Some factors might be essential in some areas but not in others. Some factors may be so important in a particular region that they compensate the absence of others. In that aspect, the study is an attempt to find out what are the social factors that influence successful resource management in developing communities like Bangladesh.

\section{Shrimp farming in Bangladesh}

The economy of coastal Bangladesh largely depends on shrimp farming. Since the 1980s, it has been playing a very important role in the country's whole economy with regard to exports and employment. It ranks second in terms of earning valuable foreign exchange after the garment industry, and there are over 600,000 people employed directly in shrimp farming who support around 3.5 million dependents (Usaid, 2006). The area of shrimp farming has expanded from 20,000 ha in 1980 to 150,000 ha in 2001 due to strong demand from international markets (Karim, 2005). Bangladesh has the fourth largest area (about 0.143 million hectares) for shrimp farming. But, beginning in 1997, farmers have been experiencing low productivity and negative profits due to the problems of disease and environmental degradation which lead to declining living conditions and economic losses. Alam (2007) found that disease outbreaks are results of unnecessary use of chemicals, lack of proper water exchange and degradation of water quality.

Shrimp farming is naturally dependent on the tidal flow of common property brackish water which flows from the rivers to the state owned main canals and sub-canals. The supply of water at farms which are far from the canals or sub-canals is usually done by using other farms private farmland. The water management is easier for the head-enders 
as their plots are adjacent to a canal, but tail-ender farmers face restricted water access, since they can exchange water only by using others private land. Due to this restricted access, the water quality degrades now and then, which affects shrimp production (Mazid, 2003). As a consequence, in many cases, the tail-enders lease out or sell their land to the head-enders, leave farming occupation and engage in other non-farm activities.

Due to high sedimentation rates, the canals become loaded with silt, and the depth of the canals as well as the tidal flow of water decreases. In some areas, this salutation becomes a severe problem and creates negative economic externalities such as poor water exchange, degradation of water quality. This leads to mismanagement of common-property brackish water, which ultimately affects yields, increases the cost of shrimp production, and reduces profits for the shrimp farmers.

In the study area, BWDB (Bangladesh Water Development Board) is officially responsible for the management and maintenance of the sluice gates by which the tidal flow of brackish water is regulated. BWDB also used to manage water user groups who are responsible for distribution of water for rice as well as for shrimp farming. But the management of BWDB has become problematic due to heterogeneity of demand for brackish water. To get rid of this problem, a considerable portion of farmers are trying to manage the canals collectively. Clearing weeds from canals, desalting the canal beds, repairing the bunds and roads along the side of the canals, are the most common forms of maintenance. Farmers contribute in terms of money and labour for collective work. Most of these units employ labour only for emergency repairs of canals, whereas some units employ for both, regular maintenance and emergency repairs.

Many studies are available on shrimp farming and its different aspects. For instance, Shah et al. (2000); Bhattacharya et al. (1999a and 1999b) analysed costs and benefits of shrimp farming. Environmental issues have e.g. been addressed by Deb (1997); Aftabuzzman (1998); Ghafur et al. (1999); Islam (1999); Dutta (2001); Manju (2000). Habib (1998); Habib (1999); Maniruzzaman et al. (2001) and Ali (2002) explained the legal issues of shrimp farming. Sultana (1994); Alauddin and Hamid (1996) investigated the social problems. Begum and Alam (2000) described the land use and conflict issues. Some literature is also available on political economy issues (Manju, 2000; Ghafur et al., 1999; Chowdhury, 2001 and Dutta, 2001). Though an unstable situation exists due to lack of proper management of water, very little research is available on this issue. This study seeks to answer: what are the characteristics of the resource using communities that influence the users to organize a resource using group and at the same time, to manage the resource collectively? The main objective of this paper is to find out the characteristics of the society which are suitable to bring forward a collective management of the brackish water in a community. Furthermore, the paper may provide some guidelines for other important common resource management problems (like forest and inland water) in Bangladesh, as well as in other developing countries.

The paper is organized as follows: The next section gives a brief overview on how common canals are used for shrimp farming in Bangladesh. Section 3 presents the theory 
and evidences from previous research endeavours. The methods employed, including data, analytical and empirical procedures are described in the fourth section. The results are presented and discussed in the fifth section, and the last section draws conclusions including some policy implications.

\section{THEORY AND EVIDENCE}

Most of the literature, available on common resource management, defines collective action as follows: It requires the involvement of a group of people who need to share interests. It involves some kind of voluntary common action that may include collective decision-making, setting and designing management rules, implementing decisions, monitoring the performed works etc. Members, or their representatives, can contribute in various ways to achieve the shared goal: Money, labour and/or in kind. The coordination takes place through a formal or an informal organization. There is a substantial debate among scholars on the factors that facilitate or impede collective action. For instance, some scholars disagree on variations in the physical characteristics of resources like scarcity, size, and proximity to markets, and how they affect the likelihood of collective action (e.g., Wade, 1987; Bardhan, 1993; Meinzen-Dick et al., 2002). Some researchers debate the importance of variations in the characteristics of resource users such as age of the resource users and salience of the resource to their livelihoods (Fujiie et al., 2005; Balland and Platteau, 1996 and Wade, 1987), while Ostrom et al., 1994; Poteete and Ostrom (2004) stress the importance of face-to-face communication. Tang (1992) broadly subdivided the factors into three categories: (i) physical and technical characteristics of the resource; (ii) characteristics of the users group and (iii) attributes of institutional arrangements. This section follows Tang's classification to recognize the variables. In the following sections, the relevant discussion have been briefly reviewed on how collective action is affected by the character of the resource, the attitudes of the resource users, and the institutional context, in different literatures.

\section{a) Physical characteristics of the resource}

Scholars agree that physical and technical characteristics of a resource affect the likelihood of persons to join an organization, as well as to get involved in collective management (Ostrom et al., 1994 and Araral, 2009). Different common resources hold different characteristics and, therefore, need different types of involvement in the management. As characteristics of the resource, the effects of scarcity of resources and distance to markets on collective action have been discussed in this section.

Most researchers who studied common resource management agreed that, the users would not come forward for collective action as long as the resource is not moderately scarce. Meinzen-Dick et al. (2002) expressed that measuring water scarcity accurately is difficult because to assess actual water supply and demand is costly. But, locations along the canals serve as a good proxy in most systems. While studying different irrigation systems, Bardhan (1993); Agrawal (2002); Ternstrom (2003) and Araral (2009) found that cooperation is more difficult when water is abundant or extremely scarce. 
The results of the effects of market access on collective action are mixed in the literature. Usually, better market access may favour collective action, since it may increase the value of the resource and the return from managing the resource. On the other hand, sites closer to markets are likely to be more commercially oriented, and the opportunity costs of labour could be relatively high. While analyzing grazing land management in Ethiopia, Gebremedhin et al. (2002) found that collective action may be more beneficial and effective in areas that are far from the market places. In communities, closer to markets, alternative resource management options such as privatization may be more effective. Ostrom \& Gardner (1993) found that increasing market pressure lessens mutual dependencies, loosens up traditional social ties, and reduces the inter-linkages for possible reprisal in the case of adverse behaviour.

\section{b) Characteristics of the user groups}

Researchers opined that the characteristics of the resource using community also influence the performance of collective management. Although the size of a user group has been stressed in many contributions, debate still continues on many other characteristics, like the dependency on the resource of the users, age and origin of the user group, heterogeneity, the rate of poverty among the users, the gender composition, trust etc. In the following paragraphs, some relevant findings have been reported, so far documented in the literature.

\section{Leadership}

Leader is defined as an individual or group of individuals who assume leading roles within the community on the decision-making process of the group's political agenda. The success or failure of any organization for common resource management depends on the entities, managing it, and engaging in rule formulation and enforcement. The wider the representation of the organization in the community is, the better the chances are in securing local cooperation for managing and preserving the resource (Celia Futemma et al. 2002). Meinzen Dick et al. (2002) found that the presence of college graduates lead farmers to form organizations for irrigation. Most probably, graduates would offer innovation and have the skills that are needed to set up and manage an organization.

\section{Social and economic heterogeneity}

The community could be heterogeneous in several aspects including socio-cultural, racial, ethnic and economic background, interests and endowments. Each of these aspects may affect collective action differently (Balland and Platteau, 1999). Olson (1965) argued that group heterogeneity is favorable for collective action. Johnson (2000) concluded that although both the social heterogeneity and economic inequality are likely to hinder cooperative efforts, the social inequality is quantitatively more important than that of economic inequality. Araral (2009) found that heterogeneity in wealth creates difficulties with respect to agreements on distribution rules, which in turn makes enforcement difficult and thus lessens the likelihood of collective action. 


\section{Age and origin of the user group}

Many researchers think that the age and origin of resource user groups are the most important factors in determining success of collective action. The view of Meinzen-Dick et al. (2002) is, members understand each other in older groups; whereas members of newer groups are less certain about teamwork with other members. Fujiie et al. (2005) also assumed that collective action is less likely when the history of irrigation is short. A contending view of Araral (2009) is that the age of the irrigation system has no statistical significance on levels of collective action. The source of the user group is also hypothesized to affect the likelihood of successful collective action among farmers. Ostrom and Shivakoti (2002) guessed that self-organized associations have a stronger sense of "ownership" identity that influences members to be more likely to work collectively, compared to government-organized associations.

\section{Group size}

The accurate size of associations has been a matter of important theoretical and policy debates. Olson (1965) hypothesized that "unless the number of individuals in a group is quite small, rational, self-interested individuals will not act to achieve their common or group interests". Since then, a significant number of researchers in economics, political science, and sociology have examined this hypothesis. Baland and Platteau (1999) repeated: "The smaller the group, the stronger its ability to perform collectively". Tang's (1992) study of irrigators also suggests that smaller groups perform better than larger ones.

The experience from traditional water user associations (WUA) in Asia suggests that it is more difficult to organize over-dimensioned WUAs. Meinzen-Dick et al. (2002) argued that smaller groups have an advantage in cooperation because all plans, activities and strategies could be clearly observable. At the same time, linkages among group members are also very important and they diminish negotiation costs. ARARAL (2009) found that increase in group size leads to an increase in transaction costs because of the reduced observability of actions. Moreover, the marginal social costs of individual defection are negligible, as compared to the marginal private gains.

On the other hand, some scholars have observed that the relationship between group size and collective action is more complex. The research findings of WADE (1987) suggest that small size is not necessary to facilitate successful collective action. Ostrom (1997) summarized that the impact of group size on collective action is influenced by a variety of other variables like the production technology of the collective good, its degree of excludability, the level of heterogeneity in the group etc. Gebremedhin et al. (2001) argued that the degree of collective action may be low when the user number is small due to huge fixed costs, as well as when the number is very large, because of increasing variable transaction costs of attaining and enforcing collective action, or because of higher competition for the resource. 


\section{c) Institutional arrangements}

Several institutions could be found in resource using communities which bring forward or impede collective action, e.g. government organizations, NGOs, religious, social or educational institutions, as well as cooperative associations. Byrnes (1992) argues that government involvement weakens the incentive towards cooperative efforts among the resource users. Meinzen-Dick et al. (2002) found that the presence of cooperatives in the community have no significant impact on the formation of an irrigation organization, instead, the number of temples influences the villagers significantly. The social capital generated by religion may have a stronger power on the successful creation of an organization for natural resource management than that of cooperatives.

\section{METHODOLOGY OF THE STUDY}

\section{Study area and data}

Khulna district is producing the highest amount of shrimp in Bangladesh. Paikgacha is the sub district at which more than $90 \%$ of agricultural land is under shrimp farming, and it has severe water management problems. For collecting information on water user groups, we discussed with 44 canal user groups through rapid rural appraisal by following a semistructured interview schedule. Questions related to the variables have not been asked directly to the group members. After every discussion meeting, the enumerator team measured those variables. Information have been collected on the number of water users in the group, distance from market to the canal, influential persons in the community, relationship with government institutions, existence of cooperative associations, social and economic similarity or heterogeneity etc. From the discussion, it was possible to draw information of approximately all canal users on the number of head and tail-enders for the same canal, as well as on the proportion of small, medium and large farmers.

\section{Defining the variables}

Four equations (models) have been used to fulfill the objectives with 4 dependent variables which are described as follows:

\begin{tabular}{|c|c|c|c|}
\hline \multicolumn{2}{|c|}{ Dependent variables } & \multicolumn{2}{|l|}{ Description } \\
\hline \multirow{2}{*}{\multicolumn{2}{|c|}{$\begin{array}{l}\text { Model 1: PROCOLMAIN } \\
\text { Model 2: DEGCOLMAIN }\end{array}$}} & \multirow{2}{*}{\multicolumn{2}{|c|}{$\begin{array}{l}\text { Probability of collective maintenance of canals ( } 1 \text { or } 0) \\
\text { Farmers' view about canal maintenance and defined as " } 3 \text { " } \\
\text { for good, "“2" for fair, or " } 1 \text { " for not good. }\end{array}$}} \\
\hline & & & \\
\hline \multicolumn{2}{|c|}{ Independent variables } & \multicolumn{2}{|l|}{ Description } \\
\hline Variable code & Variable type & Variable definition and measurement & Expected sign \\
\hline \multicolumn{4}{|c|}{ Characteristics of the resource } \\
\hline DISTMKT & Continuous & $\begin{array}{l}\text { Distance of nearest market from the canal (in } \\
\text { kilometres) }\end{array}$ & + \\
\hline SCARCE & Continuous & Number of farmers facing water scarcity. & - \\
\hline INFRA & Dummy & $\begin{array}{l}\text { Infrastructure indicates average required time } \\
\text { to travel to the nearest town from canal. If } \\
\text { farmers can reach within } 1 \text { hour, it is considered } \\
\text { as } 1 \text { and } 0 \text {, if they need more time. }\end{array}$ & t \\
\hline
\end{tabular}




\begin{tabular}{|c|c|c|c|}
\hline \multicolumn{2}{|c|}{ Independent variables } & \multicolumn{2}{|l|}{ Description } \\
\hline \multicolumn{4}{|c|}{ Characteristics of the group of users } \\
\hline Leadership & Continuous & $\begin{array}{l}\text { Number of graduates (who have } 14 \text { years } \\
\text { educational experience), in the community. }\end{array}$ & + \\
\hline GINI & Continuous & $\begin{array}{l}\text { Gini-coefficient is the measurement of the inequality } \\
\text { in land ownership among the canal users. The } \\
\text { highest Gini value has been found } 0.81 \text { and the } \\
\text { lowest is } 0.29 \text {. }\end{array}$ & - \\
\hline GRPSIZE & Continuous & Number of water users for a canal & - \\
\hline \multicolumn{4}{|c|}{ Attributes of institutional arrangements } \\
\hline ORIGIN & Dummy & $\begin{array}{l}\text { Coded as } 1 \text {, if the group was founded by members' } \\
\text { self motivation ( } 0 \text {, from Govt. management or NGO). }\end{array}$ & + \\
\hline AGE & Continuous & $\begin{array}{l}\text { How long the water users association is in existence } \\
\text { (years). }\end{array}$ & + \\
\hline BWDB & Dummy & $\begin{array}{l}\text { Coded as } 1 \text {, if group members communicate regular } \\
\text { with BWDB. }\end{array}$ & + \\
\hline NGO/COOP & Dummy & $\begin{array}{l}\text { Coded as 1, if NGO or cooperative exist in the user } \\
\text { group. }\end{array}$ & + \\
\hline OUTSIDER & Dummy & $\begin{array}{l}\text { 1, if the outsider exists and shows dominancy for } \\
\text { using canal. }\end{array}$ & - \\
\hline ORGANIZ & Dummy & If water user association exists, then it is coded as 1 . & + \\
\hline
\end{tabular}

\section{Analytical approach: Logit model}

The decision of a household to participate in collective water management takes the shape of a choice of options. When the dependent or response variable is qualitative and the outcome of the decision is a matter of probability, then the model is called qualitative response model or probability model or binary response model (Gujarati, 2003).

Three approaches have been proposed in the literature, to develop a probability model. These include the linear probability model (LPM), the Logit, and the Probit model. In this study, the Logit model will be used which is very popular because of the fact that it is designed to describe a probability which is always a number that lies between 0 and 1 . Although the Probit model is also used when the dependant variable takes binary values, the logistic function is fairly accurate as a representation of the normal distribution. It is analytically convenient (Gujarati, 2003). Mathematically the Logit model is written as:

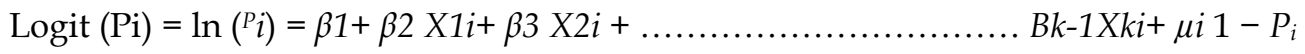

${ }^{\left({ }^{P}\right)}$ is simply the log of the odds ratio in favour of collective management i. e. the ratio of the $1-P_{i}$ probability that a water user group chooses to participate in the water management to the probability that it chooses not to participate. $\beta 1$ is the intercept term, and $X 1, X 2, X 3 \ldots \ldots \ldots, X k$ are the explanatory variables and the subscript $i$ denotes the $i^{\text {th }}$ observation in the sample. $\beta 1, \beta 2, \beta 3 \ldots \ldots \beta k$ are the coefficients to be estimated in association with each of the explanatory variables. Finally, $\mu i$ is the stochastic error term. 
Among the 4 models, model I is binary Logit model. The dependant variables are assigned a value of zero, if the group does not engage in water management or has not formed a formal group $(Y=0)$. The value is 1 , if the group engages in water management or has formed a formal group $(Y=1)$. In case of model II, we have used the ordered Logit model. Traditionally, the model has been employed in applications such as surveys, where we find more than two response categories in terms of ordinal ranking. Examples of multiple ordered response categories include opinion surveys with responses ranging from "strongly agree" to "strongly disagree," levels of state spending on government programs (high, medium, or low) etc. (Torres-Reyna, O; undated). If we suppose, $y^{*}$ is the exact but unobserved dependent variable, $x$ is the vector of independent variables, and $\beta$ is the vector of regression coefficients which we wish to estimate and $\varepsilon$ is the error term, then the model will be, $y^{*}=x^{\prime} \beta+\varepsilon$, Instead of $y^{*}$, we can only observe the categories of response $y$ $=1$, if $\mu 0 \leq y^{*} \leq \mu 1 y=2$, if $\mu 1 \leq y^{*} \leq \mu 2 y=3$, if $\mu 2 \leq y^{*} \leq \mu 3$ $\ldots y=n$, if $\mu n-1 \leq y^{*}$

The data analysis was carried out using STATA 8.2 software.

\section{FINDINGS AND DISCUSSION}

\section{Descriptive results}

There is a wide variation among groups with respect to the characteristics of the resource as well as of the user groups and institutional arrangements. In addition, variations also exist in terms of recruitment of collective labour, collection of funds and methods of cost sharing. Table 1 and 2 provides the descriptive information about the resource using community. A large proportion of the data is of a more qualitative type (with yes or no answers), because matters like cooperation and its determinants involve social and economic qualities of communities.

Table 1. Descriptive statistics of quantitative variables

\begin{tabular}{l|ccc|cc|ccc}
\hline Graduates & \multicolumn{3}{c}{ Group size } & \multicolumn{2}{c|}{ Age (AGE) } & \multicolumn{2}{c}{ Scarcity } & \multicolumn{2}{c}{ Origin of association } \\
\hline $\begin{array}{l}\text { Number of } \\
\text { graduates }\end{array}$ & $\begin{array}{c}\text { No. of } \\
\text { communities }\end{array}$ & $\begin{array}{c}\text { No. of } \\
\text { members }\end{array}$ & $\begin{array}{c}\text { No. of } \\
\text { groups }\end{array}$ & $\begin{array}{c}\text { Age } \\
\text { (years) }\end{array}$ & $\begin{array}{c}\text { No. of } \\
\text { groups }\end{array}$ & $\begin{array}{c}\text { Mean } \\
0.64\end{array}$ & $\begin{array}{c}\text { Types of } \\
\text { origin }\end{array}$ & $\begin{array}{c}\text { No. of } \\
\text { groups }\end{array}$ \\
$\begin{array}{l}\text { No } \\
\text { Graduate }\end{array}$ & 18 & $<15$ & 10 & $<10$ years & 18 & $\begin{array}{c}\text { Std. dev } \\
\text { No }\end{array}$ & 12 \\
$1-5$ & 15 & $15-30$ & 15 & $10-20$ years & 14 & Max. & Self & 15 \\
& & & & & & 0.85 & motivated & \\
$>5$ & 11 & $>30$ & 19 & $>20$ years & 11 & Min. & Govt./NGO & 17 \\
& & & & & & 0.32 & initiated &
\end{tabular}

Source: Rapid rural appraisal, 2008

Information on leadership was collected during RRA by asking about graduates and their role in the community. The graduates could be farmers themselves or their family 
members and engage in decision making in the community. They can discuss with the responsible institutions and solve any social problem within very short periods.

Table 2. Descriptive statistics for dummy variables

\begin{tabular}{l|c|c|c|c|c}
\hline $\begin{array}{c}\text { Number of } \\
\text { communities }\end{array}$ & NGO & Cooperatives & formal groups & Relation with BWDB & Outsider \\
\hline Exist $(1)$ & 21 & 23 & 32 & 16 & 15 \\
Do not exist (0) & 23 & 21 & 12 & 28 & 29 \\
\hline
\end{tabular}

Source: Rapid rural appraisal, 2008

Mainly three NGOs (named Shushilon, Uttaran and Nijera Kori) have been found in the study area to be working for the promotion of collective water management. In some communities, there are cooperative associations. The members sit together weekly/ monthly and raise limited funds equally. Normally their motive is to save some money to cope with adverse situations, like getting loans to start small businesses at the time of unemployment, or to buy food and necessary items after a cyclone or any other natural disaster. In the study area, the resource-poor farmers are mostly engaged in this kind of cooperatives; very few rich farmers cooperate with them. The communities which do not have written or semi-written documents, never arrange meetings. The associations have been asked about the number of meetings in the last three years. Some organizations were found to be very active for some years but after that period, became inactive.

\section{Analytical results}

Although successful collective action is always related to well build up organizations, its quality mainly depends on farmers' willingness to be a part of such an organization. Nevertheless, the formation of the organization is only a starting point of any management. To achieve the goals of the organization, activities are required. It has been already mentioned that 32 groups have been founding formal organizations. But only some of them are satisfied with their collective activities and some are not. If farmers' maintenance of canals and sub-canals is a way to manage water timely, we wanted to find out, what accounts for whether or not farmers are willing to take over the maintenance of the system and what the social characteristics of different groups are that influence farmers to execute well.

Using the theoretical factors suggested in the literature, logistic regression analysis is employed firstly to model the probability of farmers' collective maintenance Model II measures the determinants of success in collective maintenance of water user groups by the ordered Logit model. The analytical results are being described in the following sections.

\section{a) Physical and technical characteristics of the resource}

In this section, how the physical characteristics of resources affect collective action have been described. The findings show that market distance negatively affects collective 
management. Bangladesh is a country where the role of the market place (Bazaar) is very interesting and important. The place does not only create commercial opportunities, it also serves as an important avenue for social interactions, especially in the small tea stalls. Farmers discuss personal as well as social problems on the market place with a view to finding solutions. So, farm owners near to the market are more likely to be organized. Our explanation differs from Gebremedhin et al., (2002) and Ostrom \& Gardner (1993) who found that collective action is more beneficial for areas far away from the market. In fact, it could also be true that people, who live near the market, become less attentive to farming and are more inclined to pursue non-farm income activities. But in the study area, market is shrimp business oriented because of its backward and forward linkages.

Table 3. Probit regression results for variables affecting collective water management

\begin{tabular}{|c|c|c|}
\hline \multirow[t]{2}{*}{ Variables } & \multicolumn{2}{|c|}{ Coefficient (S. E.) } \\
\hline & Model I & Model II \\
\hline Dependent variable & PROCOLMAN & DEGCOLMAN \\
\hline Constant & $0.236^{* *}(0.091)$ & $0.363^{* *}(0.127)$ \\
\hline \multicolumn{3}{|c|}{ a. Physical and technical characteristics of the resource } \\
\hline DISTMKT SCARCE & $0.825(.393)-0.579 * *(0.270)$ & $-0.962 * *(0.381)$ \\
\hline \multicolumn{3}{|l|}{ b. Characteristics of the user groups } \\
\hline $\begin{array}{l}\text { GRADUATE OUTSIDER GINI } \\
\text { ORIGIN AGE GRPSIZE }\end{array}$ & $\begin{array}{c}0.290 *(0.107)-3.528^{*}(1.569)- \\
1.194^{*}(0.0381) 1.032 *(.4321) \\
1.045(0.719)\end{array}$ & $\begin{array}{c}2.996^{* *}(1.209)-8.432^{* *}(3.690)- \\
10.970^{* *}(4.981) 4.401^{* *}(1.958) \\
1.066^{*}(.4700)-1.220^{* *}(0.452)\end{array}$ \\
\hline \multicolumn{3}{|c|}{ c. Institutional arrangements for water management } \\
\hline $\begin{array}{l}\text { BWDB NGO COOP ORGANIZ } \\
\text { (WUA) Number of observations } \\
\text { LR chi2 Prob > chi2Pseudo R2Log } \\
\text { likelihood }\end{array}$ & 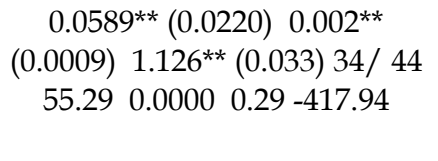 & $\begin{array}{c}0.1579 * *(0.070) 1.070(0.665) \\
9.578^{*}(4.382) 3237.690 .000 \\
0.25-470.94\end{array}$ \\
\hline
\end{tabular}

Source: Author's calculation is based on rapid rural appraisal data, 2008; ** Significant at $1 \%$ level and *significant at $5 \%$ level; standard errors are robust

It is observed from the results that if more members of the group face scarcity, they are less likely to go for collective water management due to the fact that conflicts arise among group members, and their returns are low, compared to their contributions. In this way, the location of the resource influences the users to join in a collective effort. The reasons are highly consistent with various opinions expressed in the empirical literature, for example Bardhan (1993); Dayton-Johnson and Bardhan (1999); Agarwal (2002) and Araral (2009). They found that cooperation is more difficult when water is either very scarce (due to potential conflict on water allocation) or is plentiful (because of little incentive to cooperate, since water is abundant).

\section{b) Characteristics of the user groups}

Collective action is also influenced by the socio-economic characters of the resource using community. The model results tell that the presence of graduates in the resource using community plays a significant role, may be due to the fact that the technical knowledge of 
graduates could be helpful for canal maintenance and the influential persons have strong social relationships with the community and they enjoy high acceptability in the society. At the same time, they know the networks and the way that could draw official attention to the area, which would be useful in starting an organization for resource management.

The presence of outsiders' in the community usually discourages collective resource management. In most cases, outsider farmers are relatively wealthy. They are mostly residents of urban areas, want to control the common resource and try to disorganize the local people. In some cases, outsiders offer bribes to some locals in order to dissuade other locals from participating in collective work. So, their dominancy disheartens local people to work together in organizational activities. It is a sensitive issue for collective lobbying in the area. Some farmers are willing to contribute for lobbying, but due to fear of outsiders, they fail to participate. It was found that outsider farmers have spies (Confidential informers) in the community. They report about the people who are going to arrange lobbying. As a result, the locals, even influential farmers, face harassment by the outsiders. The outsiders and are very powerful and have good relationships with politically active persons as well as with law and order forces. Sometimes, they file false cases against the locals, and police forces create problems for the victims. Even many murder cases, happening in the study area, do not receive fair justice. If the entrance of outsiders could be discouraged through the implementation of appropriate policy measures, the law and order situation around shrimp farms might improve.

Our result shows that farmers in a large group are not satisfied or are not getting their expected return. It seems that after being organized, members of large groups face conflicts with each other over time. The social cohesion among members of large groups may not be sustainable over longer time periods. Frohlich and Oppenheimer (1970) reported that the effects of group size on cooperation are conditional on how other variables are affected by changes in the size of a group. So, future tests would have to be done, in order to determine how the group size is related to other variables, like heterogeneity or inequality among the common resource users, and the benefits of the collective action.

Many researchers suggest that age and origin of resource user groups are the most important factors in determining the success of collective action. The result also shows that users of older groups are more successful in collective maintenance than newer groups (model II). Our result is consistent with the findings of Fujiie et al. (2005) and Meinzen-Dick et al. (1997). But, Ternstrom (2003) found that the age of the organization has no statistical significance on the level of collective action. With regard to the origin of the group, our findings indicate that it has significant impact on successful collective action. The reason could be similar to what Ostrom and Shivakoti (2002) found. Members of self-organized groups may have a stronger sense of ownership identity which motivates them to cooperate in collective endeavors, compared to associations organized by government agencies. 
The impact of the GINI-coefficient of land distribution is negative and significant which tells that greater resource inequality may reduce the level of collective effort. It seems that if few farmers have large resource stocks in a common resource using community, while many of them are poor, then poor users face problems. Araral (2009) mentioned three dimensions that wealth affects collective maintenance of the common resource: (i) wealth provides incentive for the rich to contribute for the maintenance of the resource despite there are some free riders; (ii) wealth can create exit options for large land owners, making collective action less likely and, (iii) heterogeneity in wealth creates problems regarding agreements on distributive rules, which makes enforcement difficult and lessens the likelihood of collective action. The second and third dimensions may have influence on the resource using communities in the study area.

\section{c) Institutional arrangements for water management}

The set up of institutional arrangements also influence the success of collective action. For instance, involvement of government institutions leads water users to work collectively in group. Farmers believe that BWDB could solve crucial problems which are difficult to solve for individuals, especially the timely maintenance of sluice gates. The same reason may also bring success for water user associations (Model II). But the result differs from the findings of Byrnes (1992), who concluded that collective efforts for Pakistani watercourses declined due to government intervention.

NGOs could to some extent play a role in resource management, though it does not influence significantly the founding of an organization due to the fact that resource users regard them as outsiders (Model I). But it could enhance the management activities of user associations by providing financial facilities, like the provision of credit, through which shrimp producers can get input supply timely. Sometimes, they also try to manage conflicts between water users, incase, they are engaged in the same NGO.

Cooperative associations significantly increase the likelihood to successfully form an organization. The underlying fact could be that cooperatives provide some motives to increase social ties. Members, who are already cooperating in other areas; are assumed to be more inclined towards collective actions. Thus, having a "cooperative mind" is very important for the common resource users. This may not evolve automatically, rather the cooperative may be asked for support. Karl Marx also argued in this way: "employees who are in regular contact with one another, develop a 'habit of cooperation' and be more likely to act collectively than employees who work in isolation" (Bennis, 1963).

The existence of water user associations (Model I) has significant effects on collective action. This indicates that organizations facilitate collective action. The formal recognition of registered organizations may empower farmers to undertake maintenance which requires coordination, like scheduling work days, determining labour and cash contributions, monitoring and supervising those who do not participate etc. In particular, regular maintenance is possible when there is an organization that makes these issues routine. Farmers' involvement can also improve the sustainability of the organizations 
themselves. Usually the association arranges general meetings, where farmers can interact with each other and exchange information. This may also increase social ties. MeinzenDick et al. (1997) found that the presence of water users associations gives farmers more trustworthiness in communicating with the authorities. Therefore, regular general meetings could also be one factor which may lead to successful collective maintenance. There are many formal and informal organizations for water management in different countries, but due to the lack of managerial guidance, they in most cases tend to become worthless. Therefore, attention should be given to ensure that organizations remain active after they have been founded.

\section{CONCLUSIONS}

The intention of this paper was to identify the basic social characters that are necessary, where the community needs to manage non-exclusive common pooled resources. Logit regression models have been employed on a data set of 44 brackish water canal user groups, located in the south west coastal areas of Bangladesh. Consistent with the empirical literature, our findings imply that collective actions in common resource management are being influenced by the characteristics of the resource, as well as the characteristics of the resource users, and the institutional structure of the community. In particular, scarcity of the resource, relations with governmental authorities, level of education, resource inequality, age and origin of the user group, existence of user associations, cooperatives and outsider's dominance in the community etc. are influencing the performance of collective resource management.

User associations strongly influence collective resource management, while resource scarcity and group size influence negatively. If users face resource scarcity, or the group size is very large, collective action slows down, although association exists in the community. It seems how users start the organization, the bond does not continue may be due to facing conflict. So, further study could be conducted on how the number of conflicts could be successfully decreased.

The existence of a market plays an important role in conducting successful collective management. It was found that in some places markets existed in the past. However, due to scarcity of drinking water and fuel, because of the expansion of the saline water, people started to move to different localities. Eventually, only very poor people with low purchasing power remained in the area. At the end, market place was shifted to another locality. The distance between the farms and the market place increased, causing fewer possibilities for the farmers to meet with each other, which, as a consequence, impeded collective action. Through this finding, we may discover an important clue that environmental degradation negatively influences collective action.

While graduates play an important role in collective action, presence of outsiders and economic inequality restrict resource users to wok together. In developing countries, if any farming or business is profitable, outsiders and wealthy people always try to enter 
and control the business sector. At the same time, they create difficulties for the locals and the poor. In many cases, the locals get out of the business. In the study area, we have found that they move to cities to seek employment. After movement, very few men get hard working jobs like rickshaw pulling, and the females get 'maid' jobs and sometimes low end positions in the shrimp industry. Most of the men remain unemployed or engage with illegal occupations. This is one example for poor countries on how locals are driven away by the outsiders in resource-rich communities. So, before implementing any other policy measures, it should be made sure that local people can keep control over their resources. Under present circumstances, appropriate steps should be taken to discourage outsiders from entering the shrimp farming business. It certainly would be useful to further study what kind of affirmative action is required to empower local farmers. Policy measures should also be taken to reduce the economic inequality.

As involvement of government organizations and resource user associations are important preconditions for a successful collective resource management; so, their joint or collaborative effort may bring advantages for the resource using community.

However, the study has also some limitations. For example, it was not possible to consider the law and order situation and to gather information about many other institutions, involved in shrimp farming. Environmental variables have also been ignored in this study. We think that before measuring the impacts of these determinants, the costs and benefits of collective action need to be assessed. Ignoring these factors may lead to insufficient evidence for policy implications. For that reason, multi and interdisciplinary analysis is required.

\section{ACKNOWLEDGEMENTS}

The first author would like to thank Professor Dr. Dr. h. c. F. Kuhlmann for his invaluable comment at different stages of this paper. Financial support from DAAD is highly acknowledged. This paper is an extension work from first author's $\mathrm{PhD}$ research.

\section{REFERENCES}

Adhikari, B. 2004. Social Inequality and Collective Action: An Empirical Study of Forest Commons. School of Natural Resources and Environment University of Michigan 440 Church Street, MI 48109, IFRI Working Paper \# W08I-5.

Aftabuzzaman, 1998. Sustainable Environment Friendly Aquaculture. Centre for Policy Dialogue Report No. 18. Centre for Policy Dialogue, Dhaka, Bangladesh.

Agrawal, A. 2002. Common Resources and Institutional Sustainability. In: E. Ostrom et al. (Eds.), The Drama of the Commons (pp. 41-85). Washington, DC: National Academy Press.

Alam, S. M. N. 2007. Biological and Chemical Products Use in Extensive Shrimp Farming in Southwest Bangladesh. J. Fish. Aquatic Sci., 2: 56-62. 
Alauddin, M. and Hamid, M. A. 1996. Shrimp culture in Bangladesh with emphasis on social and economic aspects. In P. T. Smith (Ed.). Towards sustainable shrimp culture in Thailand and the region (pp. 53-62) Canberra: Australian Centre for International Agricultural Research.

Ali, A. M. S. 2006. Rice to shrimp: Land use/land changes and soil degradation in South-west Bangladesh. Land Use Policy, 23(4): 421-435.

Araral, E. 2009. "What Explains Collective Action in the Commons? Theory with Econometric Results from the Philippines". World Development, Volume 37, Issue 3, March 2009, Pages 687-697.

Baland, J. and Platteau, J. 1996. Halting Degradation of Natural Resources: Is there a Role for Rural Communities? Oxford: Clarendon Press.

Baland, J., and Platteau, J. 1999. The Ambiguous Impact of Inequality on Local Resource Management. World Development, 27(5): 773-788.

Bardan, 1993. Symposium on Management of Local Commons. Journal of Economic Perspective, 7(4): 87- 92 .

Begum A. and Alam S. M. N. 2000. Bangladesh: Case Study-1; Social Aspects of Coastal Shrimp Aquaculture in Bangladesh. Caritas-Bangladesh (Sponsored by World Bank, NACA and FAO), Dhaka, Bangladesh

Bennis, W. G. 1963. A New Role for the Behavioural Sciences: Effecting Organizational Change. Administrative Science Quarterly, 8(2): 125-165.

BFFEA. 2001. Statement Shown Export of Frozen Food from Bangladesh, Bangladesh Frozen Foods Exporters Association, Dhaka.

Bhattacharya D., Rahman M., Khatun F. A. 1999a. Environmental Impact of Trade Liberalization and Policies for the Sustainable Management of Natural Resources: A Case Study on Bangladesh's Shrimp Farming Industry, Centre for Policy Dialogue (CPD), Dhaka, Bangladesh.

Bhattacharya D., Rahman M., Khatun F. A. 1999b. Environmental Impact of Structural Adjustment Policies: The Case of Export Oriented Shrimp Culture in Bangladesh. (CPD), Dhaka, Bangladesh.

Byrnes, K. J. 1992. Water users associations in World Bank-Assisted irrigation projects in Pakistan, Technical Paper No. 173 (The World Bank, Washington, DC).

Celia F., Castro, A. D., Silva-Forsberg, M. A. and Ostrom, E. 2002. The Emergence and Outcomes of Collective Action: An Institutional and Ecosystem Approach. Ambiente and Sociedade-Ano V-No. 10.

Chowdhury Z. H., Islam N., Bhuiyan S. and Hasan, M. 2001. Network/Political Analysis Study. Bangladesh Centre for Advanced Studies, Dhaka, Bangladesh.

Dayton-Johnson, J. and Bardhan, P. 1999. Inequality and Conservation on the Local Commons: A Theoretical Exercise. The Economic Journal, 112(481): 577-602.

Deb, A. K. 1997. Fake Blue Revolution: Environmental and Socio-Economic Impact of Shrimp Culture in the Coastal Areas of Bangladesh. Community Development Centre (CDC). Canada.

Dutta, A. 2001. Who Benefits and at What Costs? Expanded Shrimp Culture in Bangladesh. In Grassroots Voice. A Journal of Indigenous Knowledge and Development, 3(4). 
Frohlich, N. and Oppenheimer, J. 1970. I Get by with A Little Help From My Friends. World Politics, 23: 104-120.

Fujiie, M., Hayami, Y. and Kikuchi M. 2005. The Conditions of Collective Action for Local Commons Management: The Case of Irrigation in the Philippines. Agricultural Economics, 33(2): 179-189.

Gebremedhin, B., Pender, J., and Tesfay, G. 2004. Collective Action for Grazing Land Management in Crop Livestock Mixed Systems in the Highlands of Northern Ethiopia. Agricultural Systems. 82(3): 273-290.

Ghafur, A, Kamal, M. Dhaly, M. R. and Khatun, S. 1999. Socio-Economic and Environmental Impact of Shrimp Culture in South-western Bangladesh: An Integrated Approach, Nijera Kori and IDPAA at Proshika, Dhaka, Bangladesh.

Gujarati, D. 2003. Basic Econometrics, McGraw Hill, $4^{\text {th }}$ Edn.

Habib, M. E. 1998. Legal and Administrative Aspects of Shrimp Culture. In Centre for Policy Dialogue, Environmental Consequences of Export Oriented Shrimp Culture in Bangladesh, Centre for Policy Dialogue, Dhaka, Bangladesh.

Habib, M. E. 1999. Management of Fisheries, Coastal Resources and the Environment in Bangladesh: Legal and Institutional Perspectives, International Centre for Living Aquatic Resources Management (ICLARM), Dhaka, Bangladesh.

Islam, A. 1999. Effects of Shrimp Farming on the Physico-Chemical and Biological Qualities of Water. Bangladesh Agriculture University, Mymensingh. Bangladesh.

Johnson, J. D. 2000. Determinants of Collective Action on the Local Commons: A Model with Evidence from Mexico. Department of Economics, Dalhousie Uniĺersity, Halifax, NoÍa Scotia, Canada B3H 3J, Journal of Development Economics. 62: 181-208.

Karim, S. M. R. 2005. Shrimp marketing in some selected areas of Bangladesh. Unpublished MS Thesis, Department of Co-operation and Marketing, BAU, Mymensingh.

Lam, W. 1998. Governing Irrigation Systems in Nepal: Institutions, Infrastructure and Collective Action. San Francisco, CA: Institute for Contemporary Studies.

Maniruzzaman, M., Santiago, A. C., Nuruzzaman, M., Anwari, B. and Shahjahan, 2001. The Acts and Actors in Fisheries and Shrimp Sector: Final Report of Legal and Institutional Review and Study of Government Agencies. Department of Fisheries and DFID, Dhaka, Bangladesh.

Manju, T. 2000. Political Economy of Shrimp Culture in Bangladesh. Poverty Research Report 13. Grameen Trust. Bangla.

Mazid, M. A. 2003. Research Strategies for Costal Aquaculture Development in Bangladesh. Workshop Proceeding. pp. 9-18, (ed) M. A. Wahab. Environmental and Socioeconomic Impacts of Shrimp Farming Bangladesh, Bangladesh Agricultural University, Mymensingh.

Meinzen-Dick, R., Mendoza, M. S., Saddoulet, L., Abiad-Shields, G. and Subramanian, A. 1997. Sustainable Water User Associations: Lessons from a Literature Review. In A. Subramanian, N. V. Jagannathan, \& R. S. Meinzen-Dick (Eds.), User Organizations for Sustainable Water Services, World Bank Technical Paper 354, Washington, DC, World Bank. 
Meinzen-Dick, R., Raju, K. V. and Gulati, A. 2002. What Affects Organization and Collective Action for Managing Resources? Evidence from Canal Irrigation Systems in India. World Development, 30(4): 649-666.

Olson, M. 1965. The logic of collective action. Boston: Harvard University Press.

Ostom, E. and Shivakoti, G. 2002. Improving Irrigation Governance and Management in Nepal. Oakland, CA: ICS Press.

Ostrom, E. 1990. Governing the Commons: The Evolution of Institutions for Collective Action. New York: Cambridge University Press.

Ostrom, E. 2005. Collective Action Theory. In C. Boix, \& S. Stokes (Eds.), Oxford handbook of comparative politics. Oxford: Oxford University Press.

Ostrom, E. and Gardner, R. 1993. Coping with Asymmetries in the Commons: Self-governing Irrigation Systems can Work. Journal of Economic Perspectives, 7(4): 93-112.

Ostrom, E., Gardner, R. and Walker, J. 1994. Rules, Games and Common Pool Resources. Ann Arbor, MI: University of Michigan Press.

Poteete, A. and Ostrom, E. 2004. Heterogeneity, Group Size and Collective Action: The Role of Institutions in Forest Management. Development \& Change, 35(3): 435-461.

Ruth, M. R., Raju, K. V. and Gulati, A. 2002. What Affects Organization and Collective Action for Managing Resources? Evidence from Canal Irrigation Systems in India. International Food Policy. Research Institute, Washington, DC, USA.

Sultana, M. 1994. Gender, Poverty, Natural Resource Decline and Sustainable Development in Bangladesh, Mimeo.

Tang, S. Y. 1992. Institutions and Collective Action: Self Governance in Irrigation. San Francisco, CA: ICS Press.

Ternstrom, I. 2003. The Management of Common Pool Resources: Theoretical Essays and Empirical Evidence, Stockholm. The Economic Research Institute of the Stockholm School of Economics.

Usaid, 2006. http:/ / www.usaid.gov, access date 25.06.2009.

Varughese, J. and Ostrom E. 2001. The Contested Role of Heterogeneity in Collective Action: Some Evidence from Community Forestry in Nepal. World Development, 29(5): 747-765.

Wade, R. 1987. Village republics: Economic Conditions for Collective Action in South India. Cambridge, UK: Cambridge University Press. 